\title{
Pengembangan Pelatihan Pengangkutan Zat Radioaktif untuk Pemangku Kepentingan yang Terkait
}

\author{
Nanang Triagung Edi Hermawan \\ Direktorat Pengaturan Pengawasan Fasilitas Radiasi dan Zat Radioaktif \\ BADAN PENGAWAS TENAGA NUKLIR \\ Jln. Gajah Mada No.8 Jakarta Pusat 10120 Telp. (021) 63855360 \\ Email: n.triagung@bapeten.go.id
}

\begin{abstract}
Ionizing radiation, that exposed by radioactive material as part of the nuclear energy, has been used in some activities, such as in research and development, medical, and industries fields. The radioactive material utilization needs transportation supporting activities. Transport of radioactive material is a transfer of radioactive material from one place to another place through a public area, use inland, sea, or air transportation mode. Radioactive material is existent in public area when transportation is executing needs compliance with established radiation safety and security standards. By the reasons, it is needed comprehension and competency standards for each related stake holder on transport activities. A literature study on the development of training on the transport of radioactive material for each related stakeholder has been conducted. The competency standards should include knowledge, skills, and attitudes aspect. An identified competency standards should be expressed in to training subjects, includes introduction, radiation safety technical aspects, handling of radioactive material packaged in custom area, security technical aspect, procedures for escorting of dangerous goods, management system, emergency preparedness and response, administrative procedural, and practical session for handling of radioactive material packaged. For each training, subjects should be created detail basic competencies and working success indicators as a basic for developing of curricula, syllabus, teaching material and planning.
\end{abstract}

Keywords: training, radioactive material, ionizing radiation, transportation

\begin{abstract}
Abstrak
Radiasi pengion yang dipancarkan zat radioaktif sebagai bagian dari tenaga nuklir telah dimanfaatkan di berbagai bidang kegiatan, meliputi penelitian dan pengembangan, kesehatan, serta industri. Kegiatan penggunaan zat radioaktif memerlukan dukungan pengangkutan zatradioaktif. Pengangkutan zat radioaktif merupakan pemindahan zat radioaktif dari suatu tempat ketempat lain melalui jaringan lalu lintas umum, baik menggunakan angkutan darat, laut, maupun udara. Keberadaan zat radioaktif di area public pada saat berlangsungnya pengangkutan memerlukan pemenuhan persyaratan keselamatan radiasi dan keamanan sesuai standar yang berlaku. Dengan demikian dibutuhkan pemahaman dan standar kompetensi untuk setiap pemangku kepentingan terkait. Telah dilakukan kajian pustaka dalam rangka pengembangan silabus pelatihan pengangkutan zat radioaktif untuk pemangku kepentingan yang terkait. Standar kompetensi dimaksud harus mencakup aspek pengetahuan (knowledges), ketrampilan (skills), dan sikap (attitudes). Standar kompetensi yang teridentifikasi selanjutnya diwujudkan ke dalam mata pelatihan, meliputi pengantar materi, aspek teknis keselamatan radiasi, penanganan bungkusan zatradioaktif di kawasan kepabeanan, aspek teknis keamanan,
\end{abstract}


prosedur pengawalan pengangkutan bahan berbahaya dan beracun, sistem menajemen, kesiapsiagaan dan penanggulangan kedaruratan, tata laksana administratif, dan praktikum penanganan bungkusan zat radioaktif. Untuk setiap mata pelatihan harus dirumuskan rincian kompetensi dasar dan indikator keberhasilan kerja yang menjadi acuan dalam penyusunan kurikulum, silabus, hingga bahan ajar dan rencana pelaksanaan pembelajaran.

Kata-kata Kunci: pelatihan, zat radioaktif, radiasi pengion, pengangkutan

\section{PENDAHULUAN}

Penggunaan zat radioaktif sebagai bagian dari pemanfaatan tenaga nuklir di berbagai wilayah tanah air memerlukan dukungan pelaksanaan pengangkutan zat radioaktif. Pengangkutan zat radioaktif merupakan pemindahan zat radioaktif dari suatu tempat ke tempat lain melalui jaringan lalu lintas umum, baik menggunakan angkutan darat, laut, maupun udara (BAPETEN 2015). Peraturan Pemerintah Nomor 58 Tahun 2015 telah menetapkan persyaratan keselamatan radiasi dan keamanan pengangkutan zat radioaktif. Peraturan tersebut telah mengadopsi dan mengadaptasi beberapa standar yang diterbitkan oleh International Atomic Energy Agency (IAEA), diantaranya Publikasi IAEA-SSR-6 (2012 edition) (IAEA 2012), IAEA-NSS-9 (IAEA 2008), IAEA-NSS-13 (IAEA 2011), serta IAEA-TSG-2 (IAEA 2002).

Setiap pemangku kepentingan yang berkaitan dengan pengangkutan zat radioaktif harus memahami dan mampu menerapkan semua persyaratan tersebut. Pemangku kepentingan dimaksud meliputi pengguna zat radioaktif, baik sebagai pengirim atau penerima, pengangkut, personil kendaraan angkut, personil bongkar muat, petugas bandara atau pelabuhan, petugas kepabeanan, petugas dinas perhubungan, personil kepolisian, dan lain sebagainya.

Untuk dapat menanamkan pemahaman yang memadai mengenai ketentuan dan persyaratan dalam pelaksanaan pengangkutan zat radioaktif bagi pemangku kepentingan terkait sebagaimana dimaksud di atas, perlu dirancang dan dikembangkan suatu pelatihan pengangkutan zat radioaktif yang sesuai dan memadai.

Kajian dalam rangka pengembangan pelatihan pengangkutan zat radioaktif untuk pemangku kepentingan terkait ini dilaksanakan dengan tujuan antara lain:

a. merumuskan materi pelatihan yang diperlukan;

b. menentukan jumlah jam pelatihan minimal yang diperlukan;

mengembangkan indicator keberhasilan keahlian untuk setiap materi pelatihan.

\section{METODE PENELITIAN}

Kajian dalam rangka pengembangan pelatihan pengangkutan zat radioaktif untuk pemangku kepentingan terkait ini dikembangkangkan berdasarkan ketentuan persyaratan keselamatan radiasi dan keamanan pengangkutan zat radioaktif sebagaimana diatur di dalam Peraturan Pemerintah Nomor 58 Tahun 2015 (BAPETEN 2015).

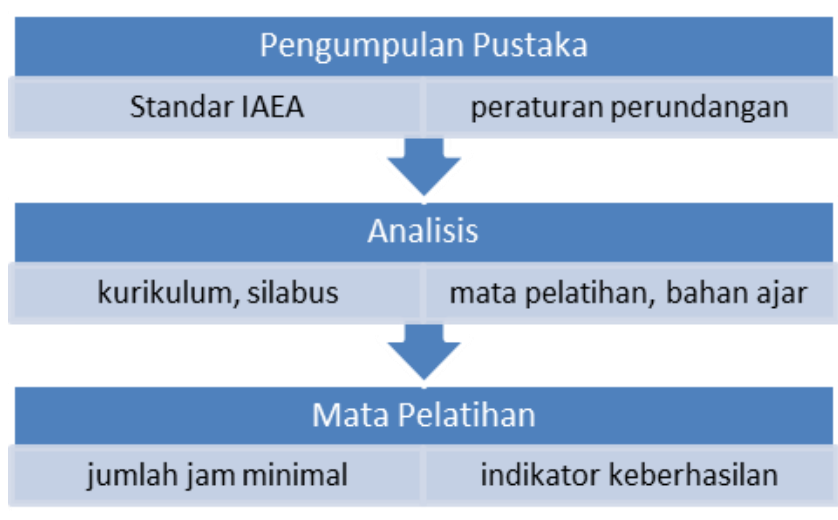

GAMBAR 1. Alur proses pelaksanaan kajian 
GAMBAR 1 menampilkan tahapan penelitian, meliputi tahapan studi pustaka, analisis, dan perumusan materi pelatihan serta indikator keberhasilan setiap mata pelatihan.

\section{HASIL DAN PEMBAHASAN}

Peraturan Pemerintah Nomor 58 Tahun 2015 (BAPETEN 2015) merupakan acuan hukum utama untuk pelaksanaan pengangkutan zat radioaktif di Indonesia. Secara umum, muatan pengaturan yang terdapat di dalam peraturan tersebut meliputi:

a. klasifikasi zat radioaktif;

b. aspek teknik keselamatan radiasi;

c. aspek teknik keamanan dalam pengangkutan zat radioaktif;

d. sistem manajemen pengangkutan zat radioaktif;

e. kesiapsiagaan dan penanggulangan kedaruratan dalam pengangkutan zat radioaktif;

f. tata laksana administratif pengangkutan zat radioaktif; dan

g. sanksi administratif.

Pemangku kepentingan terkait kegiatan pengangkutan zat radioaktif pada umumnya merupakan kalangan pekerja yang awam terhadap pengetahuan mengenai zat radioaktif dan fenomena paparan radiasi. Dengan demikian tingkatan pengetahuan yang paling diperlukan oleh personil tersebut adalah pengetahuan dasar mengenai penanganan zat radioaktif yang diangkut, baik dari aspek teknis maupun legal administratif.

Berdasarkan telaah terhadap muatan pengaturan di dalam Peraturan Pemerintah Nomor 58 Tahun 2015, maka kurikulum atau silabus pelatihan yang dapat dikembangkan sebagaimana ditampilkan di dalam TABEL 1. Dari tabel tersebut dapat dilihat terdapat 10 (sepuluh) mata pelatihan yang mencakup aspek teknis, legal administratif, maupun praktikum penanganan bungkusan zat radioaktif selama pelaksanaan kegiatan pengangkutan. Dari materi pelatihan tersebut dikembangkan indikator keberhasilan keahlian (IKK) sebagai tujuan pembelajaran yang ingin dicapai.

Mempertimbangkan cakupan dan kedalaman pengetahuan yang ingin diajarkan dalam pelatihan, setidaknya diperlukan waktu pelatihan secara keseluruhan paling kurang selama 36 jam pelajaran (JP), atau setidaknya dalam 5 (lima) hari kerja. Namun demikian pelatihan harus dikemas sedemikian dalam bentuk pelatihan publik yang memang ditujukan untuk personil-personil yang tidak harus memiliki keahlian yang mendalam dalam penanganan zat radioaktif, tetapi cukup mendapatkan dasar-dasar pengetahuan yang relatif sederhana.

Materi pengantar pengangkutan zat radioaktif ditujukan untuk mengantarkan peserta pelatihan terhadap hal-hal yang umum berkaitan dengan penggunaan zat radioaktif di berbagai bidang kegiatan, sebagai bagian tidak terpisahkan dari pemanfaatan tenaga nuklir, seperti di bidang kesehatan, industri, pertanian, ataupun penelitian dan pengembangan.

Selain itu pada materi pengantar ini juga dijabarkan penjelasan mengenai zat radioaktif sebagai bagian dari bahan berbahaya dan beracun (B3), batasan pengertian pengangkutan zat radioaktif, serta beberapa contoh pemindahan zat radioaktif yang dikecualikan dari persyaratan keselamatan dan keamanan yang telah ditetapkan.

Pada materi aspek keselamatan radiasi dalam pengangkutan zat radioaktif akan dijelaskan mengenai kelengkapan persyaratan keselamatan radiasi yang bertujuan untuk meminimalisasi potensi dan risiko bahaya radiasi yang dipancarkan dari zat radioaktif yang diangkut. Uraian persyaratan radiasi mencakup penjelasan mengenai klasifikasi zat radioaktif, bungkusan yang digunakan, ketentuan kategori bungkusan, pemasangan tanda, label, dan plakat. Khusus untuk pengangkutan bahan nuklir yang meliputi uranium, thorium, dan plutonium diperlukan pengetahuan mengenai Indeks Keselamatan Kekritisan.

Berkaitan dengan aspek keselamatan radiasi juga perlu dipahamkan format dan muatan dokumen program proteksi dan keselamatan radiasi yang mendukung pengangkutan. Tidak kalah pentingnya untuk disampaikan adalah pengetahuan berkaitan dengan ketentuan penempatan bungkusan zat radioaktif, baik pada saat persiapan pengiriman, di atas kendaraan angkut, di tempat transit, maupun setelah dibongkar dari kendaraan angkut. Dengan pemahaman keselamatan radiasi diharapkan penanganan terhadap zat radioaktif dapat berlangsung secara selamat, baik untuk pekerja yang terlibat, anggota masyarakat umum, maupun kelestarian lingkungan hidup. 
TABEL 1. Penjabaran materi pelatihan beserta jumlah jam pelajaran dan indikator keberhasilan keahlian

\begin{tabular}{|c|c|}
\hline No. & Mata Pelatihan \\
\hline 1. & Pengantar Pengangkutan Zat Radioaktif (2 JP) \\
\hline & 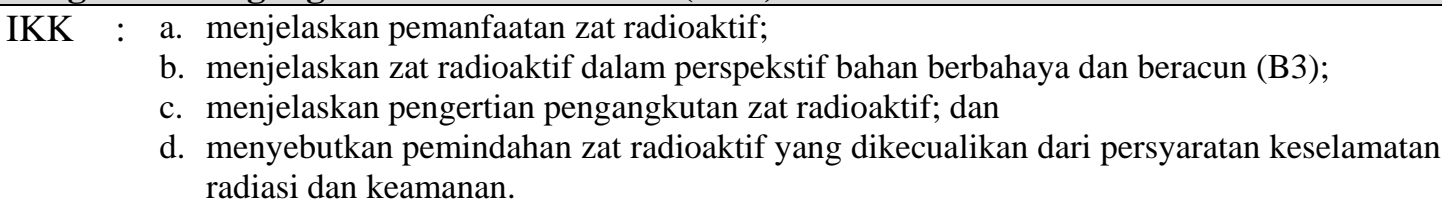 \\
\hline
\end{tabular}

2. Aspek Teknis Keselamatan Radiasi dalam Pengangkutan Zat Radioaktif (6 JP)

IKK : a. menyebutkan klasifikasi zat radioaktif, termasuk yang memerlukan sertifikat persetujuan zat radioaktif;

b. menyebutkan jenis bungkusan zat radioaktif, termasuk yang memerlukan sertifikat persetujuan desain bungkusan zat radioaktif;

c. menjelaskan kesesuaian penggunaan bungkusan zat radioaktif;

d. menjelaskan makna kategori bungkusan zat radioaktif;

e. menjelaskan maknatanda, label, dan plakat pada bungkusan zat radioaktif;

f. menjelaskan makna Indeks Keselamatan Kekritisan untuk bahan nuklir;

g. menjelaskan ketentuan pemeriksaan bungkusan zat radioaktif untuk keperluan kepabeanan;

h. menjelaskan isi dokumen program proteksi dan keselamatan radiasi; dan

i. menjelaskan ketentuan penempatan bungkusan zat radioaktif selama pengangkutan.

\section{Aspek Teknis Keamanan dalam Pengangkutan Zat Radioaktif (4 JP)}

IKK : a. menyebutkan kategorisasi sumber radioaktif;

b. menjelaskan makna tingkat dan tindakan keamanan sumber radioaktif;

c. menjelaskan rencana pengamanan sumber radioaktif selama pengangkutan;

d. menyebutkan penggolongan bahan nuklir; dan

e. menjelaskan rencana pengamanan proteksi fisik bahan nuklir.

\section{Penanganan Bungkusan Zat Radioaktif di Kawasan Kepabeanan (3 JP)}

IKK : a. menjelaskan penanganan B3 di Kawasan Kepabeanan; dan

b. menjelaskan penanganan zat radioaktif di Kawasan Kepabeanan.

5. Prosedur Pengawalan Pengangkutan B3 (termasuk zat radioaktif) oleh Kepolisian (3 JP)

IKK : a. menjelaskan ketentuan permohonan pengawalan; dan

b. menjelaskan prosedural pengawalan.

6. Sistem Manajemen Pengangkutan Zat Radioaktif (2 JP)

IKK : a. menyebutkan kewajiban pengirim, pengangkut, dan penerima;

b. menjelaskan ketentuan kelengkapan dokumen pengiriman; dan

c. menjelaskan cakupan sistem manajemen pengangkutan.

7. Kesiapsiagaan dan Penanggulangan Kedaruratan dalam Pengangkutan Zat Radioaktif (3 JP)

IKK : a. menjelaskan prosedur penanggulangan kedaruratan;

b. menjelaskan ketentuan pelatihan dan geladi kedaruratan; dan

c. menjelaskan tindakan penanggulangan kedaruratan.

8. Koordinasi Penanggulangan Kedaruratan Pengangkutan B3 (3 JP)

IKK : a. menjelaskan prosedural komunikasi dengan institusi terkait; dan

b. menjelaskan koordinasi tindakan penanggulangan kedaruratan.

\section{Tata Laksana Administratif Pengangkutan Zat Radioaktif (4 JP)}

IKK : a. menyebutkan dokumen-dokumen legalitas pengangkutan zat radioaktif;

b. menjelaskan dokumen persetujuan pengiriman;

c. menjalaskan dokumen notifikasi pengangkutan lintas batas antar negara;

d. menjelaskan makna dokumen validasi, terhadap:

- sertifikat persetujuan desain zat radioaktif;

- sertifikat persetujuan desain bungkusan zat radioaktif; dan

- sertifikat persetujuan pengiriman negara asal.

10. Praktikum Penanganan Bungkusan Zat Radioaktif (6 JP)

IKK : a. menerapkan pemenuhan persyaratan keselamatan radiasi;

b. menerapkan pemenuhan persyaratan keamanan; dan

c. menerapkan pemenuhan kelengkapan dokumen administratif. 
Adapun dalam materi aspek teknis keamanan dalam pengangkutan zat radioaktif dijelaskan secara panjang lebar bagaimana ketentuan agar zat radioaktif yang sedang diangkut tidak dicuri, dirampok, dirampas, disabotase, diserang, disandera, ataupun terkena segala macam tindakan melawan hukum oleh pihak yang tidak bertanggung jawab. Hal ini sangat penting agar zat radioaktif tidak dipergunakan untuk tindakan terorisme atau kejahatan yang dapat menimbulkan ancaman keamanan. Isu mengenai keamanan nuklir pada saat ini menjadi perhatian bersama, terutama berkaitan dengan kemungkinan penggunaan zat radioaktif untuk Radiation Dispersal Devices (RDD) atau yang lebih dikenal sebagai bom kotor.

Di samping pengangkutan zat radioaktif secara domestik, dimungkinkan pula zat radioaktif diangkut lintas batas antar negara, baik untuk pelaksanaan importasi maupun eksportasi. Dalam hal ini tentu saja zat radioaktif akan melintasi daerah kepabeanan yang biasanya berada di area pelabuhan laut maupun bandar udara. Di samping pengetahuan mengenai penanganan zat radioaktif, untuk keperluan pemeriksaan fisik pada saat bungkusan zat radioaktif berada di kawasan kepabeanan diperlukan pemahaman yang memadai mengenai prosedural yang harus dipenuhi terkait personil yang kompeten, peralatan proteksi radiasi yang memadai, serta instruksi kerja yang tepat. Materi ini diharapkan disampaikan oleh personil yang kompeten dari Direktorat Jenderal Bea dan Cukai.

Untuk keperluan keamanan, pengangkutan zat radioaktif dengan kuantitas banyak ataupun dengan tingkatan potensi bahaya radiasi yang tinggi, sangat dimungkinkan perlunya pengawalan dari satuan pengamanan maupun oleh pihak Kepolisian Republik Indonesia. Pengetahuan mengenai tata cara permohonan pengawalan maupun prosedural pelaksanaan pengawalan harus diketahui oleh personil terkait. Materi ini diharapkan disampaikan oleh personil yang kompeten dari pihak Kepolisian Republik Indonesia.

Pengetahuan mengenai kewajiban para pihak utama, meliputi pengirim, pengangkut, dan penerima, perlu diketahui oleh personil lain yang terlibat dalam pengangkutan zat radioaktif. Dalam setiap pengangkutan juga harus senantiasa dilengkapi dengan dokumen-dokumen pendukung yang menyatakan legalitas kegiatan yang dilaksanakan. Semua pengetahuan di atas dikemas dalam materi mengenai sistem manajemen. Dengan pengetahuan ini diharapkan terjalin kerja sama dan koordinasi secara tepat diantara setiap pemangku kepentingan yang terkait, terutama dengan pengirim dan penerima.

Dalam setiap kegiatan apapun senantiasa terdapat potensi penyimpangan terhadap persyaratan yang telah ditetapkan. Penyimpangan tersebut biasanya berpotensi meningkatkan peluang terjadinya insiden atau kecelakaan. Di samping itu ada pula faktor eksternal yang dapat menyebabkan hal yang tidak diinginkan tersebut terjadi. Prosedur penanggulangan keadaan darurat, pelatihan atau geladi yang memadai, serta pelaksanaan tindakan penanggulangan harus dipahami bersama. Hal inilah yang menjadikan pentingnya materi mengenai kesiapsiagaan dan penanggulangan kedaruratan dalam pengangkutan zat radioaktif.

Masih terkait dengan materi sebelumnya, tindakan penanggulangan kedaruratan tidak cukup dilakukan oleh satu pihak saja. Setiap pemangku kepentingan yang terkait harus terlibat dalam suatu jalinan koordinasi yang baik dan efektif. Kedua materi yang berkaitan dengan kesiapsiagaan, tindakan penanggulangan, dan koordinasinya ini diharapkan dapat disampaikan oleh personil yang kompetensi dari Badan SAR Nasional (Basarnas) atau Badan Nasional Penanggulangan Bencana (BNPB).

Legalitas pelaksanaan pengangkutan zat radioaktif harus didukung dengan dokumen persetujuan pengiriman dari Badan Pengawas Tenaga Nuklir (BAPETEN) dan dokumen pelengkap lain yang diterbitkan oleh instansi yang berwenang. Pengetahuan personil pemangku kepentingan terkait mengenai wujud, isi, dan kelengkapan dokumen menjadi sangat penting.

Di samping dokumen-dokumen pendukung untuk pelaksanaan pengangkutan secara domestik, yang tidak kalah pentingnya adalah dokumen-dokumen pendukung untuk pengangkutan lintas batas antar negara. Selain untuk keperluan ekspor-impor, letak geografis negara kita yang sangat strategis juga dimungkinkan untuk dilintasi oleh zat radioaktif yang diangkut antar negara mancanegara.

Pengetahuan berkaitan dengan seluk-beluk dokumen pendukung dikemas dalam materi pelatihan mengenai tata laksana administratif pengangkutan zat radioaktif.

Selain menitikberatkan kepada pengetahuan, pelatihan yang dirancang diharapkan juga dapat membekali ketrampilan yang diperlukan di lapangan dalam penanganan zat radioaktif yang sedang 
diangkut. Penangan yang dimaksud berkaitan dengan kemampuan untuk mengidentifikasi pemenuhan terhadap persyaratan keselamatan dan keamanan.

Melalui materi praktikum penanganan bungkusan zat radioaktif, setiap personil yang terlibat dapat mengetahui atau mengenali bungkusan zat radioaktif yang memenuhi ataupun tidak memenuhi ketentuan yang berlaku. Di samping itu, dari sisi teknis, personil dimaksud dapat mengenali ciri-ciri fisik bungkusan berisi zat radioaktif, potensi bahaya yang menyertai, serta tindakan penanganan yang paling aman dan tepat. Materi praktikum ini diharapkan dapat memberikan gambaran teknis di lapangan secara lebih nyata sehingga semua pengetahuan yang bersifat teoritis yang telah diberikan sebelumnya dapat diresapi dan dimengerti secara lebih nyata.

Dari pin-poin silabus yang telah dipaparkan pada bagian sebelumnya, tentu akan lebih baik lagi jika dapat disusun dan dikembangkan diktat sebagai buku pegangan untuk peserta pelatihan maupun para pengajar yang terlibat. Dengan demikian pengetahuan yang dirancang dalam pelatihan dapat lebih terbakukan dan terstandar agar dapat dikembangkan pengetahuan yang relatif seragam dan tidak menimbulkan kesalahpahaman atau perbedaan perspektif dalam penerapan di lapangan.

Khusus untuk dasar-dasar pengetahuan yang berkaitan dengan persyaratan keselamatan radiasi, buku mengenai Dasar-dasar Keselamatan Radiasi dalam Pengangkutan Zat Radioaktif (Hermawan 2015) dapat menjadi salah satu acuan pustaka yang dipergunakan.

\section{SIMPULAN}

Pelaksanaan pengangkutan zat radioaktif menyertakan potensi bahaya radiasi ataupun ancaman keamanan. Setiap pelaksanaan pengangkutan zat radioaktif harus memenuhi semua persyaratan keselamatan radiasi dan keamanan sebagaimana telah diatur di dalam Peraturan Pemerintah Nomor 58 Tahun 2015. Setiap pemangku kepentingan yang terkait dan terlibat dalam pelaksanaan pengangkutan harus memiliki pengetahuan yang memadai mengenai persyaratan-persyaratan tersebut. Pemangku kepentingan dimaksud antara lain meliputi pengguna zat radioaktif, baik sebagai pengirim atau penerima, pengangkut, personil kendaraan angkut, personil bongkar muat, petugas bandara atau pelabuhan, petugas kepabeanan, petugas dinas perhubungan, personil kepolisian, dan lain sebagainya. Untuk memiliki pengetahuan tersebut perlu dikembangkan pelatihan yang mencakup materi pengantar, aspek teknis keselamatan radiasi, aspek teknis keamanan, prosedur pengawalan pengangkutan bahan berbahaya dan beracun, sistem menajemen, kesiapsiagaan dan penanggulangan kedaruratan, tata laksana administratif, dan praktikum penanganan bungkusan zat radioaktif.

\section{REFERENSI}

BAPETEN, "Peraturan Pemerintah Nomor 58 Tahun 2015 tentang Keselamatan Radiasi dan Keamanan dalam Pengangkutan Zat Radioaktif”, BAPETEN, Jakarta, 2015;

Hermawan, N.T.E, "Dasar Keselamatan Radiasi dalam Pengangkutan Zat Radioaktif", Teknosains, Yogyakarta, 2015.

IAEA, "Nuclear Security Recommendation on Physical Protection of Nuclear Material and Nuclear Facilities", IAEA-NSS-13, IAEA, Vienna, 2011;

IAEA, "Regulation for the Safe Transport of Radioactive Material", IAEA-SSR-6, IAEA, Vienna, 2012;

IAEA, "Security in the Transport of Radioactive Material", IAEA-NSS-9, IAEA, Vienna, 2008;

IAEA, Planning and Preparing for Emergency Response to Transport Accidents involving Radioactive Material”, IAEA-TSG-2, IAEA, Vienna, 2002; 